\title{
Norma Z39.83 para circulación de fondos
}

\author{
Por Javier Alonso
}

\begin{abstract}
Resumen: Se describe la norma Z39.83, los motivos por los que hacía falta, sus orígenes desde la norma SIP (Standard interface protocol), documentos que la componen, estructura, servicios que la integran, perfiles que se usan para su implementación, su lenguaje de desarrollo (xml), y sus áreas de aplicación dentro de las bibliotecas, en especial en los consorcios. Así mismo se señala la relación de esta norma con otras, como la ISO ILL, o las posibles aplicaciones a que puede dar lugar el uso de esta norma al interactuar con otras como OpenURL.
\end{abstract}

Palabras clave: Z39.83, Préstamo interbibliotecario, Consorcios, Protocolos, OpenURL.

\begin{abstract}
Javier Alonso es licenciado en documentación por la Universidad de Granada. Durante el año 2002 ocupó el cargo de project manager para la firma IMG, Hannover, Alemania, desarrollando bases de datos documentales en Lotus Notes para la agencia MDK, Gesundheitsministerium; bibliotecario en Tórtola de $\mathrm{He}$ nares, Guadalajara, en el año 2004. Facultativo de bibliotecas del Ministerio de Cultura.
\end{abstract}

\section{Title: Standard Z39.83 for interlibrary loan}

Abstract: This article describes the Z39.83 standard, reasons for its existence, origin and development from SIP (Standard interface protocol), documents of which it consists, its structure, services encompassed, profiles used for its implementation, development language (xml), and applications within libraries, especially for consortia. The relationship with other standards like ISO ILL is emphasised, as are other possible applications that may be developed through the interaction of this standard with others, such as OpenURL.

Keywords: Z39.83, Interlibrary loan, Consortia, Protocols, OpenURL

\section{Introducción}

Las bibliotecas empezaron a informatizarse en la década de los sesenta del pasado siglo. La aportación de la informática a la labor bibliotecaria ha sido decisiva a la hora sobre todo de realizar pesadas funciones que antes se hacían a mano y consumían mucho tiempo. Eso lo sabemos todos.

Al empezar las bibliotecas a trabajar de modo cooperativo, so- bre todo para ahorrar costes, surgió el problema de la comunicación de datos, ya que se solían usar distintos sigbs (sistemas integrados de gestión de bibliotecas). Una posible solución hubiera sido acordar 
un software común, pero a parte de los problemas que surgieron, en un mundo globalizado y de libre mercado no se puede pretender que todas las bibliotecas usen un solo producto.

La solución que se ha dado ha sido el desarrollo de normas que solucionen el problema de la transferencia de información entre distintas aplicaciones. Algunas de estas normas han sido los formatos MARC en sus distintas variantes ${ }^{1}$ (para registros bibliográficos, para registros de autoridad, para fondos y localizaciones, para clasificaciones bibliográficas, etc.), Z39.50 Search and Retrieval ${ }^{2}$ e ISO ILL ${ }^{3}$ entre otras. Así mismo, hace poco han aparecido otras soluciones como son NCIP (NISO circulation interchange protocol), 3M Standard interchange protocol y Ope$n U R L$.

Sobre el formato MARC no hace falta ningún comentario ya que es muy conocido. 239.50 es una norma que permite la búsqueda simultánea de registros en varios servidores, modifica los registros encontrados según un perfil que el usuario ha definido previamente, y los devuelve al cliente que inició la búsqueda. Todo esto lleva a lo que se llama el catálogo lógico. ISO ILL permite el intercambio de mensajes entre varios sigb para poder realizar el préstamo interbibliotecario independientemente del hard- y software.

Pero a todo esto hay que añadir las nuevas normas que han aparecido recientemente, como la Z39.83.

\section{Z39.83-2002-NCIP}

La norma NCIP o Z39.83 fue aprobada por la NISO (National Information Standards Organization) de los EUA el 17 de octubre de 2002, publicándose la versión oficial a comienzos de 2003. Las compañías que desarrollan sigbs han analizado las posibles mejoras que la norma puede introducir en sus productos, y está previsto que sea 2005 el año en que se implantará definitivamente en el mercado, aunque algunas compañías se hayan adelantado a esta fecha.

\section{«Z39.83 o NCIP (NISO circulation interchan- ge protocol) se ha pensado para que sea muy flexible con otros estándares, de manera que se pueda implementar con faci- lidad en cualquier sigb (sistema integra- do de gestión de bi- bliotecas)»}

NCIP se basa en una norma anterior, SIP (standard interface protocol), que gestiona las comunicaciones entre sistemas automatizados de circulación y las nuevas herramientas de las bibliotecas, entre los que encontramos aparatos lectores de códigos de barras que los bibliotecarios usan para realizar préstamos, o las nuevas máquinas de autopréstamo, con las que los usuarios realizan el préstamo o la devolución sin intervención de los bibliotecarios, máquinas que cada vez son más usadas; otras son las que permiten a los usuarios gestionar por sí mismos otras operaciones como la reserva o renovación de préstamos. Esta norma SIP, también de la NISO, se basó en los desarrollos de la empresa $3 M$, que creó una norma de facto, por lo que su nombre completo es $3 M$ Standard interchange protocol: data transfer protocol between library automation devices and automated circulation systems (Revision 2, $1997)^{4}$.

NCIP nace con la intención de mejorar la comunicación entre los distintos sistemas (módulos) que existen en un sigb, como son el de circulación o el de préstamo interbibliotecario, así como otras aplicaciones relacionadas con ellas; también mejora las relaciones dentro de una entidad o de un consorcio, entre los distintos sigbs que pudieran existir.

La norma define un conjunto de mensajes y una serie de reglas de sintaxis y semántica que gestionan las peticiones de circulación (préstamo, devolución, renovación) entre diferentes fondos, facilita el acceso electrónico a recursos virtuales (e-revistas), realización de pagos, autentificación y actualización de fichas de los usuarios, así como las peticiones de información sobre los mismos fondos. Además, indica las condiciones bajo las cuales deben transmitirse las informaciones concernientes a los usuarios, las agencias o los ejemplares, así como las condiciones de acceso, datos fundamentales para la realización del préstamo.

Lo que la norma no hace es definir la política de circulación de una agencia o el interfaz de usuario.

Consta de dos documentos:

-Circulation interchange part 1: Protocol, que incluye una descripción de los servicios NCIP, los elementos de cada mensaje, así como un diccionario de datos;

\section{-Circulation interchange part} 2: Protocol implementation profile, que define los requisitos técnicos para la implementación por medio de $\mathrm{xml}^{5}$.

La NISO designó a la State Library of Colorado ${ }^{6}$, agencia para el mantenimiento de la norma NCIP. Así mismo existe un NCIP-IG, NISO Circulation Interchange Protocol Implementation Group ${ }^{7}$ formado en octubre de 2002 también en Denver, Colorado, cuyo cometido es promover un foro de discusión sobre aspectos técnicos relativos a esta norma, así como fomentar su uso y asesorar a los programadores.

NCIP hace posible la definición de la biblioteca híbrida al pro- 


\section{Revista sobre documentación,}

\section{bibliotecas y nuevas tecnologías}

\section{de la información}

EL PROFESIONAL DE LA INFORMACIÓN es una revista bimestral dirigida a los que trabajan en cualquier tarea relacionada con la adquisición, tratamiento documental o informático, almacenamiento y difusión de datos y documentos, así como en diseño de sistemas de información y en la enseñanza de todas estas técnicas.

Leer EPI es la forma idónea de estar al día sobre el mundo de la información y de conocer cuáles son los cambios más significativos que se van produciendo. EPI añade antecedentes e información de fondo sobre las noticias para situarlas en su contexto o compararlas. Incluye comentarios y analiza tendencias.

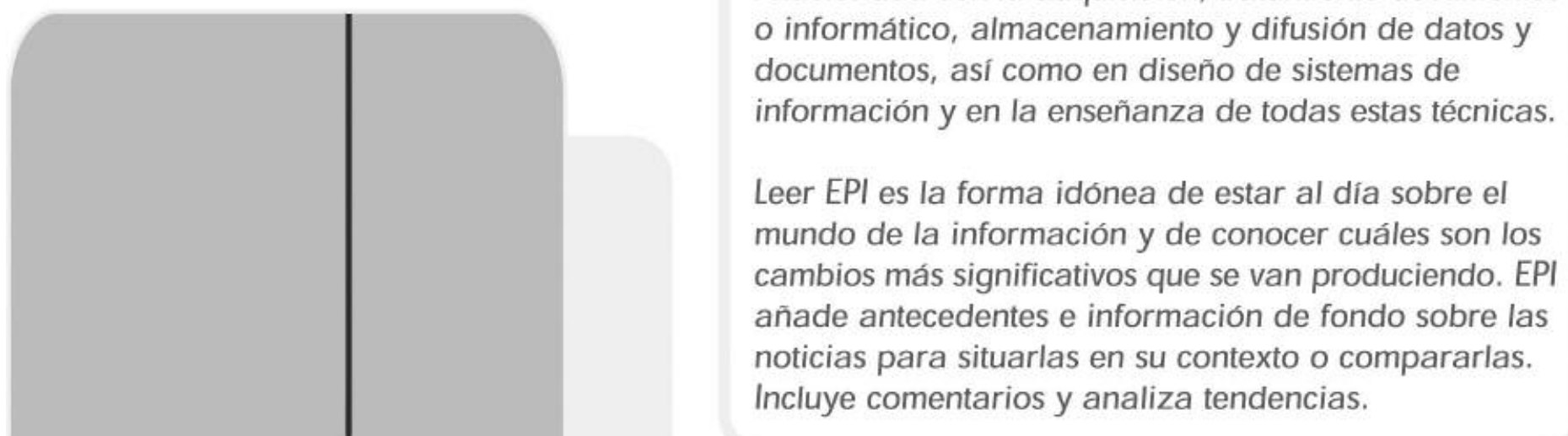

Mercado de la información: estadísticas, aspectos legales, políticas, empresas, productos y servicios Recursos informativos en las redes Sistemas de información Internet, multimedia y soportes ópticos Gestión del conocimiento Lenguajes documentales Terminología

DIRIGIDA POR:

Tomàs Baiget

Pedro Hipola

PUBLICIDAD:

Alice Keefer akeefer@arrakis.es
REDACCIÓN:

epi@elprofesionaldelainformacion.com Apartado 32.280. 08080 Barcelona
SUSCRIPCIONES

http://www.elprofesionaldelainformacion.com/suscripciones.html suscripciones@elprofesionaldelainformacion.com Apartado 32.280. 08080 Barcelona

Teléfono de atención al suscriptor: +34 609352954 
piciar una unión estable entre las bibliotecas convencional y digital. Define una serie de objetos (usuarios, agencias y ejemplares), servicios, mensajes de los cuales se componen los servicios y los elementos que componen los mensajes, así como tablas que controlan el intercambio de mensajes.

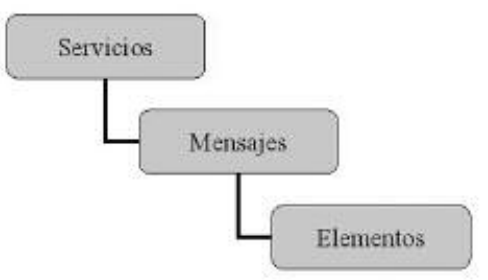

Es una norma avanzada en el sentido de que prevé que en un futuro no muy lejano grupos de instituciones asociadas, como pueden ser los consorcios, puedan compartir los datos de esos tres tipos de objetos por medio de internet o mediante una conexión directa.

\section{Estructura de NCIP}

La comunidad bibliotecaria necesitaba una norma que pudiera realizar una comunicación directa entre aplicaciones de búsqueda de registros y de préstamo, o sea, una norma que permitiera interactuar con otras como Z39.50 e ISO ILL, si no queríamos ver un panorama plagado de aplicaciones que realizaran esta función de forma independiente, con el consabido problema que a largo plazo esto podría suponer.

Pero no se quería elaborar una norma que fuera rígida en su contenido $\mathrm{y}$, siguiendo experiencias previas como la elaboración de la ISO ILL, se permitió que la norma pudiera ser flexible, que se pudiera amoldar a una serie de situaciones que se irían produciendo en las distintas bibliotecas en las que tuviera que introducirse; estas situaciones incluyen tanto el desarrollo íntegro como el parcial de la norma en los diferentes sigbs que usan las bibliotecas.
Otra de las razones para la flexibilidad venía del rápido avance de la informática y la corta duración de las aplicaciones, por lo que se decidió que NCIP usara tecnologías ampliamente introducidas en el mercado para asegurar su perdurabilidad, y que se llevara a cabo siguiendo normas ya existentes de la industria informática.

Para hacer esto posible se eligió un lenguaje de programación que fuera suficientemente flexible y "extensible" tanto para manejar los datos como el subyacente sistema de mensajes: xml; y se definieron dos perfiles de uso:

—Perfil de implementación. Especifica los mensajes y cómo se intercambian, tipo de caracteres (Unicode $\left.{ }^{8} / U T F-8\right)$, forma de codificación de los datos, componentes requeridos y su comportamiento, protocolo de transporte, seguridad, sistema de encriptación, así como normas para su desarrollo.

—Perfil de aplicación. Aclara cómo se debe usar para apoyar una aplicación concreta dadas unas pautas y políticas determinadas y las aplicaciones con las que interactúa. Incluye una descripción de los servicios que tienen que estar presentes así como los mensajes requeridos por los servicios y los datos que los conforman (texto, numérico, etc.), define las reglas bajo las que se usará la norma, puede definir requisitos de seguridad y privacidad y define el protocolo de transporte ${ }^{9}$.

Este método asegura la introducción de la norma permitiendo que se adapte a tecnologías futuras. Pueden añadirse nuevas listas de valores, pero no añadirse éstas a un protocolo ya existente; así mismo no se pueden definir nuevos objetos ni otros protocolos para el transporte, redefinir elementos ya especificados en un protocolo o convertir datos requeridos en opcionales $^{10}$. Además, como ventaja, los perfiles no dependen de ninguna tecnología particular.

Otra de las características de NCIP es la posibilidad que brinda para ejercer un control de acceso, permitiendo definir diferentes niveles de seguridad según los derechos de acceso de cada usuario. Ejemplo de niveles:

Usuarios generales (público)

Personal (staff)

Senior

Adulto

Adolescente

Niño

Usuarios privilegiados (académicos)

Personal (staff)

Profesor

Doctorando

Licenciado

Estudiante

A esto hay que añadir que NCIP permite la omisión de algunos datos solicitados por un servicio de búsqueda. Por ejemplo, al solicitar información sobre un usuario es posible que la agencia (biblioteca o institución) que responda oculte la información sobre la dirección, siguiendo su propia política.

\section{«Se trata de una nor- ma que se adelanta al futuro intercambio de información sobre usuarios, ejemplares e instituciones, y en- tre grupos de éstas asociadas, como pueden ser los con- sorcios"}

En cuanto a la autentificación, cada agencia tiene un ID único, esto es, un número irrepetible que la identifica y diferencia de las de- 
más. Además, cada usuario, ejemplar y petición tienen asignados un ID que a su vez contiene el ID de la agencia. Esta información se transmite en las cabeceras (NCIP headers) de los mensajes, lo cual permite filtrar o controlar los permisos necesarios para acceder a un tipo concreto de información o servicio. Otra de las funciones de las NCIP headers, es asegurar la integridad de los datos.

La implementación y uso de estos encabezamientos se puede observar en el programa Innopac de Sirsi (empresa que participó en el grupo de trabajo de la NISO).

Como ya se ha dicho, NCIP define tres tipos de objeto: Agencia, Item y Usuario.

El objeto Agencia ${ }^{11}$ se refiere a una biblioteca u otra organización que puede prestar ejemplares (ítems) de su colección o proporcionar cierto tipo de servicios a uno o más tipos de usuarios. Está compuesto de los siguientes elementos (los dejamos en el inglés original):

\section{Agency address information}

Agency user privilege type

Application profile supported type

Authentication prompt

\section{Consortium agreement}

Organization name information

El objeto Item representa una entidad física, como pueda ser un ejemplar de una revista, o una entidad lógica (electrónica), como una revista electrónica, perteneciente a una colección de una agencia que puede prestarse. Está compuesto de los siguientes elementos:

\section{Bibliographic description}

\section{Circulation status}

\section{Electronic resource}

Hold queue length
Item description

Item use restriction type

Location

Physical condition

Security marker

Sensitization flag

El objeto User representa una persona u organización que puede adquirir privilegios para usar los ejemplares de una agencia en particular. Sus elementos son:

Authentication input

Block or trap

Date of birth

Name information

User address information

User language

User privilege

\section{Visible user ID}

La norma también define un diccionario de datos donde se reflejan los mensajes y los elementos necesarios, definiciones, ejemplos, tipo de datos (timeldate, string, etc.), ocurrencias de uso, etc.

Los mensajes NCIP se pueden emitir a través de varios protocolos de transporte de internet como tcp/ip, http o s-http, que es un método más seguro de comunicación cliente-servidor haciendo uso de algoritmos de encriptación para cifrar el contenido de los mensajes.

Los servicios NCIP definen cada uno una serie par de mensajes que se intercambian entre los distintos sistemas en los que el proceso tiene lugar, por ejemplo dos sigbs de dos universidades. Hay dos categorías de mensajes, los iniciadores, que como el nombre indica, inician una transacción, y los de respuesta, que aportan datos en respuesta a los iniciadores.

La aplicación que envía un mensaje iniciador espera hasta que recibe el mensaje de respuesta o hasta el time-out (tiempo límite fijado previamente); sin embargo, para ahorrar el coste de establecimiento de una conexión, se puede ejecutar una conexión "latente" (idle) que permite recibir un grupo de mensajes.

\section{«Se basa en estánda- res de facto ya exis- tentes, como los de la empresa 3M»}

NCIP define tres tipos de servicio: búsqueda, actualización y notificación, estando formados a su vez por un número de servicios:

Búsqueda (lookup services). Son peticiones de información de un sistema a otro sobre una agencia, un usuario o un ejemplar, como por ejemplo la información sobre un usuario que quiere realizar una petición de préstamo a otra biblioteca; no realizan una búsqueda de usuarios sobre el sistema, como haría por ejemplo Z39.50.

Actualización (update services). Son peticiones entre distintos sistemas para realizar diversas gestiones, como renovar un ejemplar a un usuario, crear un objeto - por ej., un usuario-, modificar el estado de un objeto o incluso borrarlo.

Notificación (notification services). Actúan una vez que se ha producido una actividad en el sistema, como es la actualización de información en el fichero del usuario una vez que se ha concedido un préstamo, o si un ejemplar ha sido enviado o recibido. La notificación la inicia el sistema que ha realizado la acción y la envía al que solicitó realizar dicha operación. La notificación tienen como función enviar datos que se solicitan y confirmar implícitamente que previamente se ha recibido un mensaje.

Ejemplo: un usuario de la biblioteca $A$ de Alicante intenta pedir en préstamo un ejemplar de un li- 
<LookupUserResponse>

\section{Ejemplo de lookup user response extraído de la web de la NISO'2}

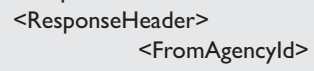

$<$ UniqueAgencyld>

<Scheme>http://www.niso.org/ncip/vI_0/imp I/schemes/uniqueagencyid/testagencies.scm $</$ Scheme $>$

$</$ UniqueAgencyld $>$

$<$ Value $>$ ORDLIB $</$ Value $>$

$</$ FromAgencyld $>$

$<$ ToAgencyld $>$

$<$ UniqueAgencyld $>$

$$
<\text { Value }>\text {....... }<\text { /Value }>
$$

$</$ UniqueAgencyld $>$

$</$ ToAgencyld $>$

$<$ /ResponseHeader $>$

$<$ UniqueUserld>

$<$ UniqueAgencyld>

<Scheme>http://www.niso.org/ncip/vl_o/imp I/schemes/uniqueagencyid/testagencies.scm</Scheme $>$

$<$ Value $>$ ORDLIB $</$ Value $>$

$</$ UniqueAgencyld $>$

$</$ UniqueUserld $>$

$<$ UserldentifierValue $>$ | $234567890</$ UserldentifierValue $>$

\section{$<$ UserOptionalFields>}

$<$ Namelnformation $>$

$<$ PersonalNamelnformation>

$<$ StructuredPersonalUserName>

$<$ GivenName $>$ Caitlin $</$ GivenName $>$

$<$ Initials $>$ AL $</$ Initials $>$

$<$ Surname>O'Brien</Surname>

$</$ StructuredPersonalUserName $>$

$</$ Namelnformation $>$

$</$ PersonalNamelnformation>

<UserAddressInformation>

$<$ UserAddressRoleType $>$

<Scheme>http://www.niso.org/ncip/vI_o/imp I/schemes/useraddressroletype/

useraddressroletype.scm $</$ Scheme $>$

$<$ Value $>$ Home $<$ /Value $>$

$</$ UserAddressRoleType $>$

$<$ PhysicalAddress $>$

$<$ StructuredAddress $>$

$<$ LocationWithinBuilding $>$ Apt. $\mathbf{C}</$ LocationWithinBuilding $>$

$<$ Street $>$ 5423 Armistead Lane $</$ Street $>$

$<$ Locality $>$ Dublin</Location>

$<$ Region $>$ OH $<$ /Region $>$

$<$ PostalCode $>430$ I $7</$ PostalCode $>$

$</$ StructuredAddress $>$

<PhysicalAddressType $>$

<Scheme>http://www.niso.org/ncip/vI_0/imp I/schemes/physicaladdresstype/

physicaladdresstype.scm $</$ Scheme $>$

$<$ Value $>$ Postal Address $</$ Value $>$

</PhysicalAddressType>

$</$ PhysicalAddress $>$

$</$ UserAddressInformation $>$

<DateOfBirth>200 I-06-0 I T | 3:00:00Z </DateOfBirth>

<UserLanguage>

<Scheme>http://lcweb.loc.gov/standards/iso639-2/termcodes.html</Scheme>

$</$ UserLanguage $>$

$<$ Value $>$ eng $</$ Value $>$

$<$ UserPrivilege $>$

$<$ UniqueAgencyld>

<Scheme>http://www.niso.org/ncip/vI_0/impI/schemes/uniqueagencyid/testagencies.scm</Scheme $>$

$<$ Value $>$ ORDLIB $</$ Value $>$

$</$ UniqueAgencyld $>$

$<$ AgencyUserPrivilegeType $>$

<Scheme>http://www.niso.org/ncip/vI_0/imp I/schemes/agencyuserprivilegetype/public.scm</Scheme> $<$ Value $>$ Child $<$ /Value $>$

$</$ UserPrivilege $>$

$<$ AgencyUserPrivilegeType $>$

$</$ UserOptionalFields $>$

$</$ LookupUserResponse $>$ 
bro a la biblioteca $B$ de Barcelona. La biblioteca $B$ envía un mensaje lookup user a la biblioteca $A$ solicitando la información de ese usuario. El servidor de $A$ envía un lookup user response que incluye la información del usuario (nombre, dirección, fecha de nacimiento, ejemplares prestados, ejemplares solicitados, NIF o CIF); esta información se transmite en formato $\mathrm{xml}$ y se usa para buscar al usuario en cuestión. En realidad, bastaría con enviar el ID del usuario, método normalmente usado para facilitar al servidor el trabajo y no sobrecargar ni la red, ni al mismo servidor.

El servidor $B$ ejecuta el servicio lookup item para buscar el ejemplar en cuestión; al encontrarlo se ejecuta lookup item response. Cuando la biblioteca $A$ recibe la respuesta, se toman los datos de la estructura $\mathrm{xml}$, se añaden al sistema de circulación de la biblioteca $A$, y se cobra el servicio de préstamo.

Todo el conjunto de mensajes contenidos en la norma NCIP, tanto iniciadores como de respuesta, describe minuciosamente las operaciones que ocurren en el departamento de circulación de una biblioteca. Son los que siguen:

\section{Lookup Services}

Autentificate user

Lookup agency

Lookup item

Lookup user

Lookup version

Agency Created
Agency Updated
Circulation Status Change Reported
Circulation Status Updated
Item Checked In
Item Checked Out
Item Created
Item Recall Cancelled
Item Recalled
Item Received

Item Renewed

Item Request Cancelled

Item Request Updated

Item Shipped

Item Updated

User Created

User Fiscal Transaction Created

User Notice Sent

User Updated

\section{Areas de aplicación}

Las principales son:

-Préstamo consorcial directo

-Circulación/préstamo interbibliotecario

—Autoservicio de circulación

Cada una de esas áreas usa un grupo diferente de mensajes para funcionar, por lo que se hace necesaria la presencia de perfiles que describan las áreas de aplicación, las funciones, que identifiquen a todas las aplicaciones participantes, que definan reglas de ejecución por las cuales se gestionen las transacciones de circulación, así como privilegios, renovaciones, tarifas, etc., e indique cuáles de los servicios deben ser usados.

Actualmente existen unos ocho perfiles de aplicación, aunque es posible que a éstos se les unan otros más en el futuro. Hay que dejar claro que los perfiles no forman parte de la norma NCIP ya que los

$\begin{array}{lc} & \text { Update Services } \\ \text { Accept Item } & \text { Renew Item } \\ \text { Check In Item } & \text { Report Circulation Status Change } \\ \text { Ckeck Out Item } & \text { Request Item } \\ \text { Undo Check Out Item } & \text { Cancel Request Item } \\ \text { Create Agency } & \text { Send User Notice } \\ \text { Create Item } & \text { Update Agency } \\ \text { Create User } & \text { Update Circulation Status } \\ \text { Create User Fiscal Transaction Update Request Item } \\ \text { Update Item } & \text { Update User } \\ \text { Recall Item } & \text { Cancel Recall Item }\end{array}$

miembros de NISO no han votado todavía sobre este asunto que se está discutiendo actualmente ${ }^{13}$.

Cuando NCIP se integre completamente en el repertorio de las operaciones de los sigbs se identificarán y añadirán más áreas adicionales de aplicación.

\subsection{Préstamo consorcial di- recto}

Permite al sistema ejecutar acciones de circulación para personas sobre ejemplares no pertenecientes al mismo, esto es, permite a los usuarios de una biblioteca pedir y prestar directamente ejemplares a otra biblioteca que pertenezca al mismo consorcio. Otra de las ventajas es que se asume que las bibliotecas no tienen que tener en común el mismo sigb.

Como es sabido, en los últimos años se han desarrollado los consorcios de bibliotecas, existiendo en cada país una legislación para definir su constitución jurídica y sus funciones. Los consorcios se forman:

—mediante acuerdo escrito,

—al unirse bibliotecas que reúnen alguna característica o interés común,

— cediendo a las demás el uso de alguno de los servicios, para obtener un beneficio u objetivo común. 
Por medio de la cooperación intentan ofrecer a sus usuarios mejores y más completos servicios.

Muchos acuerdos consorciales tienen una base geográfica, permitiendo a los usuarios de las instituciones que forman parte de cierta área geográfica, por ejemplo, pedir un préstamo a cualquier biblioteca del sistema; de este tipo son $\mathrm{Ma}$ droño ${ }^{14}, C B U C^{15}$, etc., si nos centramos en España. Otros consorcios se basan en la temática, siendo el caso de las bibliotecas especializadas como $\mathrm{Cl}$ (medicina) o Documat (matemáticas).

\section{«Al permitir la comu- nicación entre los sistemas de présta- mo interbibliotecario y de circulación, existe la posibilidad de que el concepto de préstamo interbi- bliotecario desapa- rezca como un tipo distinto de préstamo»}

El proceso por el cual dentro de un consorcio se pedía en préstamo un ejemplar de una biblioteca a otra - transacción de circulación- era lento y muy burocratizado. A veces en las bibliotecas universitarias había un departamento de correo que se ocupaba del préstamo interbibliotecario, por lo que era necesario un sistema de control del flujo de la información entre departamentos que resultaba complejo y no falto de problemática.

Con la informatización se produjeron cambios positivos: reducción del tiempo que se necesitaba para ejecutar una orden de préstamo interbibliotecario, reducción del personal ocupado de ello, redistribución de las tareas de los bibliotecarios y reducción de costes, entre otros. Pero todavía quedaba una serie de problemas que solventar.
A parte de rellenar el usuario formularios de la biblioteca que poseía el ejemplar que deseaba, lo cual no dejaba un registro en la propia biblioteca del usuario - asunto de gran importancia-, podía darse el caso de que el ejemplar en cuestión no estuviera en ese momento disponible al préstamo por no estar presente o por haberse cambiado el estatus del ejemplar, así como por otros muchos motivos (este problema concreto se pretende solucionar con la norma ISO 10324 para fondos y localizaciones).

Con NCIP, cuando un usuario pide en préstamo un ejemplar a una biblioteca en la que consta su registro como usuario, ésta envía un mensaje a la biblioteca de la que parte el mensaje, solicitando información sobre el usuario con una simple petición lookup user query (posibilidad para el préstamo, número de ejemplares que puede solicitar, información de contacto, etc.). La respuesta de la biblioteca que solicita el préstamo, lookup user query response, se escribe automáticamente en el fichero de préstamo de la biblioteca a la que se ha dirigido el usuario y la transacción se completa. Como ventaja añadida el sistema de circulación de la biblioteca que solicita el préstamo puede ser avisado de la transacción, como se explicará en el siguiente punto 4.2 .

Otras funcionalidades del préstamo consorcial directo incluyen la búsqueda y localización de fondos, devoluciones, renovaciones y otras más.

Los perfiles asociados a esta área de aplicación son:

\section{-Item agency manages tran- saction $^{16}$}

-User agency manages transaction $^{17}$

- Broker application manages transaction $^{18}$
-User agency manages transactions with proxy checkout ${ }^{19}$

\subsection{Circulación/préstamo interbibliotecario}

NCIP CILL (circulation/interlibrary loan) intercambia mensajes entre el software de gestión de préstamo interbibliotecario y el sistema de circulación de la biblioteca permitiendo a las bibliotecas usar el sistema de circulación para permitir a los propios usuarios gestionar los préstamos interbibliotecarios; así mismo, reduce el personal necesario que tiene como misión cotejar entradas repetidas de préstamos, reduciendo la carga de trabajo de los bibliotecarios, pudiéndose trabajar en otras tareas.

En la actualidad existe una desconexión total entre los sistemas de gestión del préstamo interbibliotecario y el de circulación; dentro de la biblioteca se mantienen dos sistemas que deberían compartir información, ya que el préstamo interbibliotecario no deja de ser un tipo de préstamo, y por lo tanto deberían aplicárseles a los usuarios los sistemas de control normales dentro del sistema de circulación, como son las notificaciones de tiempo de vencimiento, número máximo de ejemplares que todavía el usuario puede solicitar, multas, etc., que normalmente no se usan, todo ello con objeto de mantener un registro de cada transacción de los usuarios. Los mensajes NCIP permiten la comunicación entre ambos sistemas.

El proceso se inicia desde el sistema de préstamo interbibliotecario al enviar un mensaje al de circulación solicitando un ejemplar. El usuario recibe un mensaje desde este sistema con información relativa a su estatus dentro del sistema de préstamo, o sea, información sobre el número máximo de ejemplares que puede pedir en préstamo y cuántos tienen derecho 
todavía a pedir, reclamaciones, expiraciones, etc.

Cuando se devuelve el documento, el departamento de circulación envía un mensaje al sistema de préstamo interbibliotecario advirtiendo de la operación. De esta manera, al realizar un usuario una operación se transfiere la información entre ambos sistemas, lo que permite gestionar de forma más eficiente los usuarios este servicio.

Los perfiles son los siguientes:

-Borrowing agency ${ }^{20}$ (peticionaria)

-Lending agency ${ }^{21}$ (prestataria)

Al desarrollarse estos perfiles se han tenido en cuenta experiencias previas como los protocolos ISO ILL $L^{22}$ y su perfil IPIG ${ }^{23}$, pero su ventaja principal es que permite a aplicaciones que no se basen en estos protocolos funcionar si reconocen los eventos típicos de una transacción de préstamo interbibliotecario. El primero de los perfiles se refiere a la institución (biblioteca) que solicita el préstamo, y el segundo a la institución que va a efectuar el préstamo. Ambos perfiles permiten el seguimiento físico de los ejemplares, cuándo se prevé que llegue el ejemplar, fechas expiradas, etc.

\subsection{Autoservicio}

Permite la comunicación entre el sistema de circulación de la biblioteca y otros programas ajenos al sistema sin necesidad de realizar ningún tipo de cambios en el mismo. El origen parte de los productos de autoservicio para el préstamo, basados en normas como la anteriormente citada 3M Standard interchange protocol. Esta norma se usó además para otras aplicaciones, como sistemas de gestión de impresión que permiten controlar el uso de las impresoras por los usuarios, filtrar contenidos de internet o sistemas de pago para que los usuarios puedan imprimir, copiar, pagar multas por atraso, pérdida o daños a ejemplares, etc. ${ }^{24}$

Todo esto posibilita al usuario realizar cierto tipo de operaciones sin ayuda del personal de la biblioteca y sin la necesidad de tener que estar físicamente en la misma.

Una diferencia fundamental con respecto a los otros perfiles es que las los servicios de las aplicaciones de autoservicio son siempre iniciadas por el cliente y las respuestas las proporciona el sistema de circulación.

Los perfiles son los siguientes:

\section{-Unmediated online circula-} tion $^{25}$

-Unmediated online circulation with offline recovery ${ }^{26}$

Unmediated Online Circulation with Offline Recovery (circulación online sin intermediario con recogida offline) se usa para efectuar operaciones que se pueden llevar a cabo sin estar conectados los sistemas de circulación y los aparatos de autoservicio, por ejemplo cuando ocurre una desconexión con el servidor pero hay que seguir realizando operaciones; posteriormente, al restablecerse la comunicación con el servidor, las operaciones se actualizan en el mismo.

\section{NCIP y otros protocolos}

A parte de las tres áreas de actuación arriba descritas, NCIP se ha diseñado para interconectar una serie de protocolos de forma eficiente; supongamos el caso de que existe un consorcio (agency) en el que se usan distintos sigbs (algo que ocurre por ejemplo en Madroño, por citar alguno); supongamos que un usuario (user) desea un ejemplar (item) y que dicho usuario procede a realizar la búsqueda en su catálogo pero no lo halla. Entonces hace una búsqueda simultánea en varios servidores que perte- necen al consorcio gracias a Z39.50, obteniéndose como resultado el ejemplar en cuestión. Se procede a realizar la petición por medio de una aplicación integrada en el mismo terminal cliente basándose en el protocolo ISO ILL loan request. Es en este momento cuando ocurre el tráfico de información relativa al usuario y al ejemplar entre las dos bibliotecas.

Toda esta información tiene que ser compartida con el sistema de préstamo interbibliotecario y circulación de la biblioteca que solicita el préstamo (evidentemente, si el usuario está en condiciones de pedir este servicio), y de esta última parte se ocupa NCIP.

Pero la funcionalidad de NCIP no termina ahí, como se verá, pues sirve igualmente para comunicarse con otros protocolos.

\section{Otras aplicaciones de NCIP en bibliotecas}

6.1. Enlace con OpenURL. La industria de sistemas de gestión de bibliotecas está desarrollando lentamente productos basados en $N C I P$, una norma que, como se ha dicho, se escribió para interoperar con otras normas que ya existen. Al permitir la comunicación entre los sistemas de préstamo interbibliotecario y de circulación, existe la posibilidad de que el concepto de préstamo interbibliotecario desaparezca como un tipo de préstamo.

La norma OpenURL $L^{27}$ recientemente aprobada por NISO (para la identificación y recuperación de materiales en web citados en libros y revistas) también ofrece la posibilidad de enlazar con NCIP. Pero hay que explicar algo más en qué consiste OpenURL: es una sintaxis para transferir metadatos embebidos en enlaces URL de forma ordenada, que suele describir y nos lleva hasta un artículo o un título de revista. Tomando como ejemplo el siguiente, vemos que se define 
una serie de elementos identificativos del artículo, ISSN, volumen, número, etc. ${ }^{28}$

Castillo, Jesús. Fundamentos teóricos del análisis de contenido en la narración secuencial mediante imágenes fijas: el cómic. En: $E l$ profesional de la información, 2004, julio-agosto, v. 13, n. 4, pp. 248-271.

Cada editor o distribuidor online usa diferentes formatos de Ope$n U R L$. En el caso de EPI (ISSN 1386-6710), distribuido por la empresa Metapress, el OpenURL para el anterior artículo es:

http://www.metapress.com/openurl . asp? genre $=$ article $\&$ issn $=1386$ -

$6710 \&$ volume $=13 \&$ issue $=4 \& \mathrm{spag}$ $e=248$

Este URL se envía a un servidor que lo descompondrá en sus elementos (cada elemento se separa por un ampersand " $\&$ ") y procesará la información, buscará si el usuario tiene derecho de acceso a ese artículo en concreto y creará enlaces a referencias de catálogo a los que el usuario puede acceder.

En vez de un enlace OpenURL que muestra una referencia al catálogo de una biblioteca, podría fácilmente crear un mensaje NCIP para poner un ejemplar en disposición de ser prestado. De esta manera el usuario final no sólo puede usar OpenURL para localizar un texto concreto, sino que además lo situaría para ser prestado ${ }^{29}$. Otros usos que se le pueden dar es permitir una conexión entre un artículo en su forma resumida (ficha bibliográfica con resumen) y su forma a texto completo, o entre una descripción de un libro en una biblioteca y la descripción del mismo libro en una librería.

6.2. Metasearching. Es una nueva función que consiste en realizar una única búsqueda simultánea en bases de datos a través de un único interfaz, haciendo uso de las posibilidades de autentificación de NCIP para los usuarios, y dando cuenta de la información de fondos y localizaciones de los ejemplares. Para verificar la identidad de un usuario se usa el fichero de préstamo y el servicio lookup user. La autentificación se hace una sola vez, y se utiliza un único lenguaje de búsqueda. Como ventaja presenta una reducción en el tiempo de búsqueda.

Quizá el mayor potencial para los nuevos productos y funcionalidades que implementen NCIP es el software de los clientes que interactúan con el sistema de circulación de la biblioteca. Productos como los gestores de impresión (print managers), $P C$ reservation agents, filtros de autentificación, $\mathrm{y}$ estaciones de autopréstamo ya se encuentran en uso. Otros productos, actualmente ni siquiera imaginados, evolucionarán y usarán el mecanismo NCIP en los años venideros.

\section{Notas}

1. http://www.loc.gov/marc/

2. http://www.loc.gov/z3950/agency/

3. http://www.collectionscanada.ca/iso/ill/main.htm

4. http://cms.3m.com/cms/US/en/0-170/ ckceiFQ/viewimage.jhtml

5. http://www.niso.org/standards/resources/ z3983pt1rev1.pdf y http://www.niso.org/ standard/resources/z3983pt2.pdf

6. http://www.cde.state.co.us/NCIP/index.htm

7. http://www.cde.state.co.us/ncip/NCIP-IG.htm

8. http://www.unicode.org/

9. http://www.cde.state.co.us/ncip/meetings/ppt/14

10. http://www.cde.state.co.us/ncip/meetings/ ppt/DTDs_XMLSchemas.ppt

11. Traducción literal de la norma. La información de estos tres objetos ha sido tomada de la dirección siguiente, en sus páginas 5 y 6 :

http://www.niso.org/standards/resources/z3983 pt1rev1.pdf

12. http://www.niso.org

13. http://www.niso.org/standards/resources/ Z39.83-ApplProfiles.html

14. http://www.consorciomadrono.net

15. http://www.cbuc.es

16. http://www.niso.org/standards/resources/ NCIP-DCB-1.pdf
17. http://www.niso.org/standards/resources/ NCIP-DCB-2.pdf

18. http://www.niso.org/standards/resources/ NCIP-DCB-3.pdf

19. http://www.niso.org/standards/resources/ NCIP-DCB-4.pdf

20. http://www.niso.org/standards/resources/ NCIP-CILL-1.pdf

21. http://www.niso.org/standards/resources/ NCIP-CILL-2.pdf

22. Interlibrary Loan Application Standards Maintenance Agency

http://www.collectionscanada.ca/iso/ill/

23. http://www.collectionscanada.ca/iso/ill/ document/ipigwp/profile/ipv3_1.pdf

24. http://www.tlcdelivers.com/onlinenewsletter/ pastarticles/artmarch20044.html

25. http://www.niso.org/standards/resources/ NCIP-SS-2.pdf

26. http://www.niso.org/standards/resources/ NCIP-SS-2.pdf

27. http://library.caltech.edu/openurl/default.htm

28. http://www.serialssolutions.com/alourl03.asp

29. http://www.tlcdelivers.com/onlinenewsletter/ pastarticles/artjune20043.html

\section{Bibliografía}

1. Nye, Julie Blume. "Recent developments in standards for resource sharing". En: Journal of library administration, 2004, v. 40.

2. TLC makes NCIP toolkit available. Consultado en: 14-11-2004.

http://www.tlcdelivers.com/onlinenewsletter/pa starticles/artjune20033.html

3. Needelman, Mark H. NCIP and other protocols. Consultado en: 17-11-2004.

http://www.cde.state.co.us/ncip/meetings/ppt/ OtherProtocols.ppt

4. NISO. Protocol and implementation profile Consultado en: 17-11-2004.

http://www.niso.org/committees/committee_at. html

5. NISO. Application Profiles. Consultado en: 17-11-2004.

http://www.niso.org/standards/resources/ Z39.83-ApplProfiles.html

6. NCIP Implementers forum. Consultado en: 17-11-2004.

http://www.lib.uchicago.edu/staffweb/groups/ ncip/

7. http://www.serialssolutions.com/home.asp

8. http://www.metapress.com

\section{Javier Alonso}

alonso_francisco@gmx.net 